\title{
Dual Modes of Munc18-1/SNARE Interactions Are Coupled by Functionally Critical Binding to Syntaxin-1 N Terminus
}

\author{
Mikhail Khvotchev, ${ }^{1}$ Irina Dulubova, ${ }^{3,4}$ Jianyuan Sun, ${ }^{1}$ Han Dai, ${ }^{3,4}$ Josep Rizo, ${ }^{3,4}$ and Thomas C. Südhof ${ }^{1,2,5}$ \\ Departments of ${ }^{1}$ Neuroscience, ${ }^{2}$ Molecular Genetics, ${ }^{3}$ Biochemistry, and ${ }^{4}$ Pharmacology and ${ }^{5}$ Howard Hughes Medical Institute, University of Texas \\ Southwestern Medical Center, Dallas, Texas 75390
}

The SM (Sec1/Munc18-like) protein Munc18-1 and the soluble $N$-ethylmaleimide-sensitive factor attachment protein (SNAP) receptor (SNARE) proteins syntaxin-1, SNAP-25, and synaptobrevin/VAMP (vesicle-associated membrane protein) constitute the core fusion machinery for synaptic vesicle exocytosis. Strikingly, Munc18-1 interacts with neuronal SNARE proteins in two distinct modes (i.e., with isolated syntaxin-1 alone in a "closed" conformation and with assembled SNARE complexes containing syntaxin-1 in an "open" conformation). However, it is unclear whether the two modes of Munc18/SNARE interactions are linked. We now show that both Munc18/ SNARE interaction modes involve the same low-affinity binding of the extreme syntaxin-1 N terminus to Munc18-1, suggesting that this binding connects the two Munc18/SNARE interaction modes to each other. Using transfected cells as an in vitro assay system, we demonstrate that truncated syntaxins lacking a transmembrane region universally block exocytosis, but only if they contain a free intact $\mathrm{N}$ terminus. This block is enhanced by coexpression of either Munc18-1 or SNAP-25, suggesting that truncated syntaxins block exocytosis by forming an untethered inhibitory SNARE complex/Munc18-1 assembly in which the N-terminal syntaxin/Munc18 interaction is essential. Introduction of an $\mathrm{N}$-terminal syntaxin peptide that disrupts this assembly blocks neurotransmitter release in the calyx of Held synapse, whereas a mutant peptide that does not disrupt the SNARE complex/Munc18 assembly has no effect. Viewed together, our data indicate that binding of Munc18 to the syntaxin $\mathrm{N}$ terminus unites different modes of Munc18/SNARE interactions and is essential for exocytic membrane fusion.

Key words: neurotransmitter release; synaptic vesicle exocytosis; SNARE proteins; membrane fusion; FRET; calyx of Held; Munc18; SM proteins

\section{Introduction}

At the most fundamental level, all forms of exocytosis require two conserved protein families that participate in all membrane fusion reactions: membrane-anchored soluble $\mathrm{N}$-ethylmaleimide-sensitive factor attachment protein (SNAP) receptor (SNARE) proteins and Sec1/Munc18-like proteins (SM proteins). SNARE proteins form a complex with each other via their conserved $\sim 70$ residue SNARE motifs (Sutton et al., 1998). Synaptic vesicle exocytosis is mediated by the neuronal SNARE proteins synaptobrevin/vesicle-associated membrane protein (VAMP) on the vesicles and SNAP-25 and syntaxin-1A/1B on the plasma membrane. Synaptobrevin and SNAP-25 are "minimal" SNARE proteins composed of one or two SNARE motifs, respectively, and of membrane anchor sequences. In contrast, syntaxins are more complex and contain an additional large $\mathrm{N}$-terminal region consisting of a short natively unstructured $\mathrm{N}$-terminal sequence, an autonomously folded $\mathrm{H}_{\mathrm{abc}}$ domain (Fernandez et al., 1998), and a linker sequence (see Fig. 1A). The

\footnotetext{
Received May 1, 2007; revised Sept. 10, 2007; accepted Sept. 16, 2007.

This work was supported by National Institutes of Health Grants R01-MH69585-01 (T.C.S.) and NS37200 (J.R.) We thank Iza Kornblum and Iryna Huryeva for excellent technical assistance.

Correspondence should be addressed to Dr. Mikhail Khvotchev, Department of Neuroscience, University of Texas Southwestern Medical Center,6000 Harry Hines Boulevard, Dallas, TX75390. E-mail:mkhvoc@mednet.swmed.edu. I. Dulubova's present address: Reata Pharmaceuticals Inc., 2801 Gateway Drive \#150, Irving, TX 75063. D0I:10.1523/JNEUROSCI.3655-07.2007

Copyright $\odot 2007$ Society for Neuroscience 0270-6474/07/2712147-09\$15.00/0
}

N-terminal region confers two alternative conformations onto plasma membrane syntaxins: a "closed" conformation in which the $\mathrm{H}_{\mathrm{abc}}$ domain folds back onto the SNARE motif, thus preventing its assembly into SNARE complexes, and an "open" conformation in which the SNARE motif is exposed to participate in the SNARE complex (Dulubova et al., 1999).

SM proteins are cytosolic $\sim 600$ aa proteins with a conserved arch-shaped structure (Misura et al., 2000; Bracher and Weissenhorn, 2001). The SM protein Munc18-1 mediates synaptic vesicle exocytosis (for review, see Rizo and Sudhof, 2002; Brunger, 2005; Jahn and Scheller, 2006). The central role of SM proteins in fusion is illustrated by the observation that in mice, deletion of Munc18-1 disrupts neurotransmitter release more severely than deletion of either synaptobrevin or SNAP-25 (Verhage et al., 2000; Schoch et al., 2001; Washbourne et al., 2002). Munc18-1 interacts with SNARE proteins by two mutually exclusive mechanisms: it binds to closed syntaxin-1 in a binary complex (Dulubova et al., 1999) and to SNARE complexes in a heteromultimeric assembly (Dulubova et al., 2007; Shen et al., 2007). The first interaction mode is not observed for other SM proteins, except for the ubiquitous Munc18-1 homolog Munc18-2, whereas the second interaction mode resembles that of other SM proteins, including Munc18-3, that appear to generally bind to assembled SNARE complexes (Carr et al., 1999; Dulubova et al., 2002; Carpp et al., 2006; Latham et al., 2006; Togneri et al., 2006). 
The finding of two Munc18/SNARE interaction modes raised several questions. How can two sets of essential membrane fusion proteins participate in distinct interactions in the same fusion reaction? How are these interaction modes coupled? Are these interaction modes essential for fusion? Here, we show that the two Munc18-1/SNARE interaction modes involve a common binding of Munc18-1 to the syntaxin-1 $\mathrm{N}$ terminus that closely resembles the previously described binding of the SM proteins Sly1, Vps45, and Munc18-3 to short N-terminal sequences in their cognate syntaxins (Dulubova et al., 2002, 2003; Yamaguchi et al., 2002; Carpp et al., 2006). The N-terminal syntaxin-1 binding couples the two Munc18-1/SNARE interaction modes to each other and is essential for the membrane fusion. Our data suggest a general principle of SM and SNARE protein function in exocytic membrane fusion that involves distinct compartmentspecific modes of their interaction and a universal interaction of SM proteins with SNARE complexes.

\section{Materials and Methods}

Plasmids, proteins, and reagents. Expression vectors for human growth hormone, various syntaxin fragments, Munc18-1, and SlyI were described previously (Dulubova et al., 1999; Yamaguchi et al., 2002; Matos et al., 2003; Khvotchev and Sudhof, 2004). We used standard PCR-based procedures to introduce point mutations, deletions, or fusions and verified newly generated constructs by sequencing. Constructs for bacterial expression of syntaxin-1A fragments were generated by subcloning PCR products into pGEX-KT vectors (Hakes and Dixon, 1992). Recombinant proteins were expressed as glutathione $S$-transferase (GST) fusions in bacteria, affinity purified on glutathione-Sepharose beads (Amersham Biosciences, Piscataway, NJ), released from the GST moiety by on-resin cleavage with thrombin (Sigma, St. Louis, MO), and further purified by ion exchange and size-exclusion chromatography.

Secretion assays. Secretion assays were described in detail previously (Khvotchev et al., 2003; Khvotchev and Sudhof, 2004). For measurements of regulated exocytosis, PC12 cells were cotransfected with pHGHCMV5 and test plasmids at a 1:1 ratio using Fugene 6 transfection reagent (Roche, Indianapolis, IN). Secretion was measured at basal and stimulation conditions (using high-potassium solutions or $\alpha$-latrotoxin) by radioimmunoassay (Nichols Institute Diagnostics, San Clemente, $\mathrm{CA}$ ) and calculated as percentage from the total human growth hormone (hGH) produced by cells. For measurements of constitutive exocytosis, HEK293 and HeLa cells were cotransfected with pHGHCMV5 and test plasmids at a 1:20 ratio using Fugene 6. Secretion was determined by measuring amounts of hGH accumulated in the medium and normalized to the amount of hGH remaining in transfected cells.

Fluorescence resonance energy transfer assays. Fluorescent Munc18-1 (monomeric Cerulean-labeled) and syntaxin-1A (Venus-labeled) proteins were produced in HEK293 cells. For initial test experiments, fluorescence resonance energy transfer (FRET) was measured in whole cells that were cotransfected with both fluorescent proteins. For all other experiments, transfected cells were disrupted by sonication in the buffer containing $150 \mathrm{~mm} \mathrm{NaCl}, 25 \mathrm{~mm}$ HEPES, pH 7.6, 1 mм EDTA, and 1\% $\mathrm{BSA}$, and lysates were cleared by ultracentrifugation. Lysates were mixed so that each sample initially contained the same amount of Cerulean and Venus fluorescence and were incubated on ice for $2 \mathrm{~h}$ to allow Munc181/syntaxin-1A complex formation. Fluorescence emission measurements were performed on a model LS55 spectrofluorimeter (PerkinElmer, Wellesley, MA). Spectra were collected twice and averaged for each sample between 450 and $550 \mathrm{~nm}$ in $0.5 \mathrm{~nm}$ increments at $25^{\circ} \mathrm{C}$. The excitation wavelength was set to $433 \mathrm{~nm}$ with both the excitation and emission slit widths set to $5 \mathrm{~nm}$. In addition, Venus fluorescence was monitored by recording emission at $528 \mathrm{~nm}$ with excitation wavelength set to $515 \mathrm{~nm}$.

Nuclear magnetic resonance spectroscopy. Uniform ${ }^{15} \mathrm{~N}$ or ${ }^{13} \mathrm{C}$ labeling of protein fragments was achieved by growing the bacteria in M9 minimal medium containing ${ }^{15} \mathrm{NH}_{4} \mathrm{Cl}$ or ${ }^{13} \mathrm{C}_{6}$-glucose (CIL, Andover, MA) as the sole source of nitrogen or carbon, respectively, with wither $\mathrm{H}_{2} \mathrm{O}$ or
$\mathrm{D}_{2} \mathrm{O}$ as a solvent. ${ }^{1} \mathrm{H}-{ }^{15} \mathrm{~N}$ heteronuclear single quantum coherence (HSQC) spectra of syntaxin-1A fragments in the presence or absence of the recombinant Munc18-1 proteins were acquired on a Varian (Palo Alto, CA) INOVA 800 instrument at $27^{\circ} \mathrm{C}$ in a buffer containing $20 \mathrm{~mm}$ sodium phosphate, $\mathrm{pH} 7.1,150 \mathrm{~mm} \mathrm{NaCl}$, and $2 \mathrm{~mm}$ DTT. For the experiments with full-length Munc18-1, the syntaxin-1A ${ }^{2-243} /$ Munc18-1 complex was initially assembled at low protein concentration (below 10 $\mu \mathrm{M}$ ) and concentrated to $0.2 \mathrm{~mm}$ final protein concentration using a 30,000 MNWL concentrator (Millipore, Bedford, MA) to prevent precipitation of Munc18-1. One-dimensional (1D) ${ }^{13} \mathrm{C}$-edited ${ }^{1} \mathrm{H}$ nuclear magnetic resonance (NMR) spectra of Munc18-1/SNARE complexes in the presence or absence of syntaxin-1A N-terminal sequence peptides were obtained as described by Dulubova et al. (2007). Spectra obtained for the isolated peptides at identical concentrations were subtracted from the spectra obtained for the Munc18-1/SNARE complex/peptide samples to remove the contribution from the natural abundance of ${ }^{13} \mathrm{C}$ in the peptides. All data were processed with the NMRPipe (Delaglio et al., 1995) and analyzed with NMRView (Johnson and Blevins, 1994).

Measurements of exocytosis at calyx of Held. Preparation of slices (200 $\mu \mathrm{m}$ thickness) and whole-cell recordings of the nerve terminal were performed mostly as described previously (Borst et al., 1995; Wu and Borst, 1999). Presynaptic whole-cell recordings were made with an EPC-9 amplifier (HEKA Elektronik, Lambrecht, Germany). The presynaptic series resistances $(<15 \mathrm{M} \Omega$ ) were compensated by $60 \%$ (lag, $10 \mu \mathrm{s}$ ). Presynaptic currents were low-pass filtered at $5 \mathrm{kHz}$ and digitized at 20 $\mathrm{kHz}$. Capacitance measurements were obtained with an EPC-10 amplifier together with a software lock-in amplifier (PULSE version 8.66; HEKA Elektronik). A sinusoidal stimulus was applied in addition to the DC holding potential $(-80 \mathrm{mV})$. The peak-to-peak voltage of the sine wave was $<60 \mathrm{mV}$ to avoid activation of $\mathrm{Ca}^{2+}$ currents, and the sinewave frequency was $1 \mathrm{kHz}$. Data were processed by IGOR 3.1 and SigmaPlot 2000 (version 6.00), using homemade programs for noise filtering and presynaptic current integrations.

\section{Results}

\section{Mechanism of syntaxin inhibition of exocytosis}

Using transfected cells as an extended in vitro system, we showed previously that a soluble syntaxin-1A fragment containing residues 1-243 (syntaxin-1 $\mathrm{A}^{1-243}$ ) potently inhibits regulated exocytosis in neuroendocrine PC12 cells and constitutive exocytosis in HEK293 and HeLa cells (Khvotchev and Sudhof, 2004) (Fig. 1). This inhibitory effect operates late in the secretory pathway in all types of exocytosis and all cells investigated, suggesting that syntaxin- $1 \mathrm{~A}^{1-243}$ acts on a conserved feature of the exocytic membrane fusion machinery. To investigate the mechanism of this inhibition, we examined whether shorter syntaxin-1A fragments also inhibit exocytosis. Small additional C-terminal truncations of syntaxin- $1 \mathrm{~A}^{1-243}$ dramatically decreased its inhibitory effect on regulated exocytosis in PC12 cells and on constitutive exocytosis in HEK293 cells, with syntaxin-1 $\mathrm{A}^{1-230}$ being almost inactive in both assays (Fig. $1 B, C, H$, gray bars).

Syntaxin- $1 \mathrm{~A}^{1-243}$, which inhibits exocytosis, and syntaxin$1 \mathrm{~A}^{1-230}$, which does not, differ in two major properties: syntaxin$1 \mathrm{~A}^{1-243}$ tightly binds to Munc18-1 and forms SDS-resistant SNARE complexes with synaptobrevin/VAMP and SNAP-25, whereas syntaxin-1 $\mathrm{A}^{1-230}$ does neither (Matos et al., 2003) (supplemental Fig. 1, available at www.jneurosci.org as supplemental material). These differences suggest that syntaxin-1 $\mathrm{A}^{1-243}$ might impair exocytosis indirectly by sequestering endogenous cognate SM proteins and/or SNARE proteins, thereby depleting the cell of these essential components of the fusion machinery. Indirect inhibition may work in all cells because syntaxin-1A binds to all three Munc18 isoforms and also promiscuously engages in SNARE complexes with various exocytic SNARE proteins (Fasshauer et al., 1999; Yang et al., 1999; Dulubova et al., 2003). It is also possible that syntaxin- $1 \mathrm{~A}^{1-243}$ impairs exocytosis directly 
A

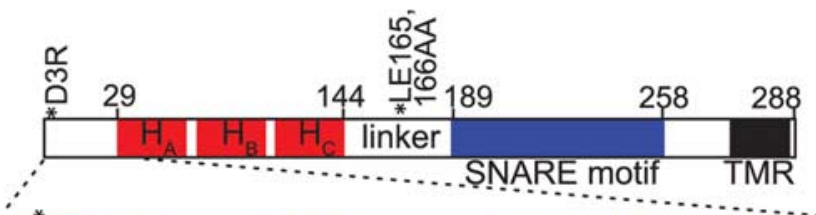

Synt1A MKDRTQELRTAK--DSDDDDDV------TVTVDRDRFMDEFFEQVEEIRG̈F̈İ 45 Synt1B MKDRTQELRSAK--DSDDEEEV--------VHVDRDHFMDEFFEQVEEIRGCIE 44 Synt2 MRDRLPDLTACRK--SDDGDNA------VIITVEKDHFMDAFFHQVEEIRSSIA 46 Synt3 MKDRLEQLKAKQLTQDDDTDEV------EIAIDNTAFMDEFFSEIEETRLNID 47 Synt 4 MRDRTHELRQGDNI-SDDEDEVRVALVVHSGAARLSSPDDEFFQKVQTIRQTMA 53 Synt5A MSCRDRTQEFLSACKSLQSRQNGI----QTNKPALHATRQCSEFTLMARRIGKDLS 52

B

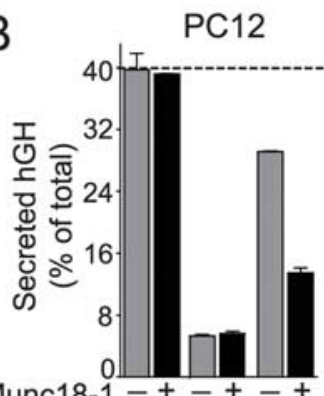

Munc18-1-

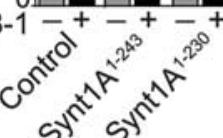

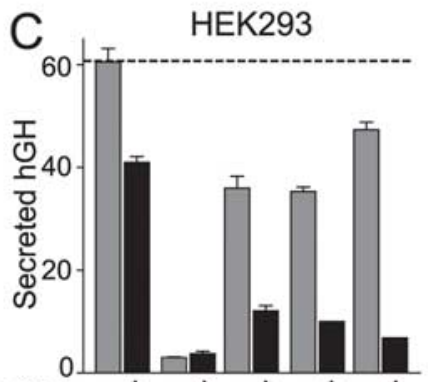

Munc18-1

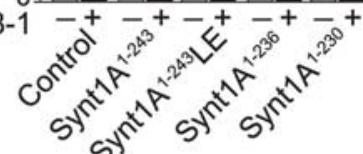

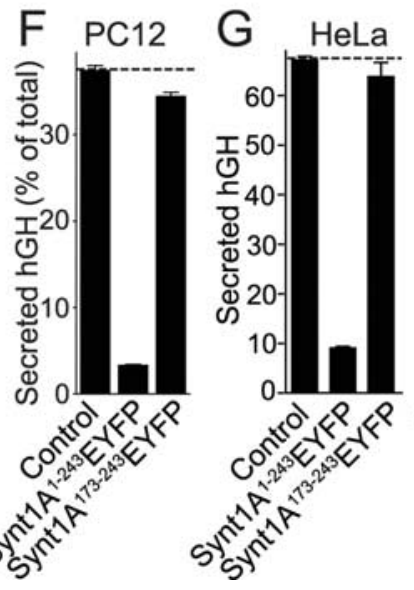

$\mathrm{H}$

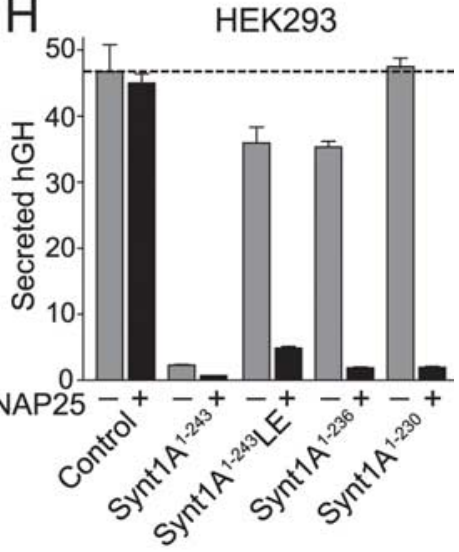

Figure 1. Syntaxin-mediated inhibition ofregulated and constitutiveexocytosis involves Munc18-1 and SNAP-25 binding.A,Domain structure of syntaxin-1. Amino acid residues are numbered on top and on the right of the alignment. The conserved $\mathrm{N}$-terminal sequences of syntaxin-1 to -5 (Synt $1 \mathrm{~A}-5 \mathrm{~A}$ ) are aligned below, with shared residues highlighted in blue. Residues critical for the syntaxin-5A/Sly1 interaction and corresponding residues in other syntaxins are shown in red. The D3 position (D5 for syntaxin-5A) is marked with an asterisk. TMR, Transmembrane region. $\boldsymbol{B}, \boldsymbol{C}$ Munc18-1 potentiates theinhibition of exocytosis bysyntaxin-1Afragments [which act by blocking fusionatthe plasma membrane (Khvotchevand Sudhof, 2004)]. Data shown are assays of regulated exocytosis in PC12 cells (stimulated with $56 \mathrm{mmK}^{+}$for $15 \mathrm{~min}(\boldsymbol{B})$ and of constitutive exocytosis in HEK293 cells (C). Cells were cotransfected with an hGH reporter vector and various expression vectors as indicated; exocytosis was measured $72 \mathrm{~h}$ $(\boldsymbol{B}, \boldsymbol{F})$ or $48 \mathrm{~h}(\boldsymbol{C}-\boldsymbol{E}, \boldsymbol{G}, \boldsymbol{H})$ after transfection. Regulated exocytosis in $\mathrm{PC} 12$ cells sis shown as the difference in release of hGH (calculated as the fraction oftotal $h G H$ produced) between stimulated and control cells. ConstitutivehGH releaseis displayed astheratio of extracellular-to-intracellularhGHfor a given sample. $\boldsymbol{D}$, Sly1 relieves the inhibition of $\mathrm{hGH}$ secretion by syntaxin-5A, which blocks the secretory pathway in the Golgi complex. $\boldsymbol{E}$, The inhibitory activity of syntaxin-1A ${ }^{1-243}$ is reversed by mutations that impair stable SNARE complex formation butnotMunc18-1 binding (L205D and 1209D) (Matos et al., 2003) (see supplemental Fig. 3, available at www.jneurosci.org as supplemental material). $\boldsymbol{F}$, G, The isolated SNARE motif of syntaxin-1A is unable to inhibit regulated $(\boldsymbol{F})$ or constitutive $(\boldsymbol{G})$ exocytosis. Syntaxin- $1 A^{1-243}$ and syntaxin- $1 A^{173-243}$ were $C$-terminally fused to EYFP (to stabilize expression). Both EYFP-fusion proteins form SDS-resistant SNARE complexes in cells (see supplemental Fig. 4, available at www. jneurosciorg as supplemental material). $\boldsymbol{H}$, SNAP-25 potentiates the inhibition of exocytosis mediated by syntaxin-1A fragments similar to Munc18-1. Errorbars indicateSEM.

by forming an inhibitory complex, which could consist of the binary Munc18/syntaxin-1 ${ }^{1-243}$ complex and/or the SNARE complex/Munc18 assembly containing syntaxin-1 $\mathrm{A}^{1-243}$.

To differentiate between these hypotheses, we tested whether

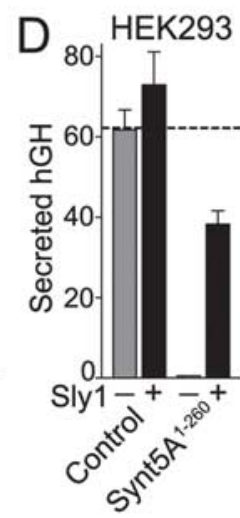

coexpressed Munc18-1 alters the ability of syntaxin-1A fragments to impair exocytosis. If syntaxin- $1 \mathrm{~A}^{1-243}$ simply sequestered endogenous Munc18, coexpression of Munc18-1 should alleviate its inhibitory effect. However, Munc18-1 did not change the inhibitory activity of syntaxin- $1 \mathrm{~A}^{1-243}$, nor did it by itself significantly inhibit exocytosis. Instead, coexpressed Munc18-1 converted the smaller, truncated syntaxin-1A fragments that do not inhibit exocytosis into potent inhibitors of exocytosis (Fig. 1B,C).

We next tested whether the closed conformation of syntaxin- $1 \mathrm{~A}^{1-243}$ was important for its inhibitory activity. Consistent with previous data (Dulubova et al., 1999), mutant syntaxin- $1 \mathrm{~A}^{1-243}$ containing the "LE" substitution that opens syntaxin-1 was a poor inhibitor of exocytosis. By rendering syntaxin- $1 \mathrm{~A}^{1-243}$ predominantly open, the LE mutation decreases the Munc18-1/syntaxin-1A binding affinity $\sim 100$-fold, but it does not completely abolish Munc18-1/syntaxin-1 binding (supplemental Fig. 2, available at www. jneurosci.org as supplemental material). Strikingly, when we coexpressed Munc18-1 with LE mutant syntaxin-1 $\mathrm{A}^{1-243}$, we observed an increase in the inhibition of exocytosis (Fig. 1C).

Viewed together, these results indicate that syntaxin- $1 \mathrm{~A}^{1-243}$ inhibits exocytosis not by depleting the cell of endogenous Munc18, but by forming a complex with endogenous or coexpressed Munc18. This mechanism differs from that of the soluble fragment of syntaxin-5A (residues 1-260, equivalent to syntaxin- $1 \mathrm{~A}^{1-243}$ ), the inhibition of transport through the Golgi complex of which is reversed by coexpression of its cognate SM protein Sly1, consistent with the notion that syntaxin- $5 \mathrm{~A}^{1-260}$ inhibits exocytosis by sequestering endogenous Slyl (Fig. 1D).

Next, we examined whether SNARE complex formation is required for inhibition of exocytosis by syntaxin- $1 \mathrm{~A}^{1-243}$. We introduced mutations that reduce the stability of SNARE complexes formed by syntaxin- $1 \mathrm{~A}^{1-243}$ [L205D and I209D (Matos et al., 2003)] but retain Munc18-1 binding (supplemental Fig. 3, available at www. jneurosci.org as supplemental material). These mutations partly (I209D) or almost completely (L205D) abolished the inhibitory effects of syntaxin-1A fragments on exocytosis (Fig. $1 E$ ), suggesting that syntaxin- $1 \mathrm{~A}^{1-243}$ has to assemble into stable SNARE complexes to inhibit exocytosis. However, SNARE complexes do not by themselves inhibit exocytosis because expression of the partial SNARE motif of syntaxin- $1 \mathrm{~A}^{1-243}$ (i.e., residues 189-243) had no effect on exocytosis (Fig. $1 F, G$ ). In testing the 
effect of SNARE complexes, we used an enhanced yellow fluorescent protein (EYFP) fusion protein of syntaxin-1 $\mathrm{A}^{189-243}$ because the partial SNARE motif of syntaxin-1A ${ }^{1-243}$ alone was not detectably expressed in transfected cells, whereas it was abundantly produced and formed stable SDS-resistant SNARE complexes after EYFP fusion (supplemental Fig. 4, available at www.jneurosci.org as supplemental material). A control EYFP fusion protein of syntaxin-1A ${ }^{1-243}$ potently inhibited regulated and constitutive exocytosis, demonstrating that the EYFP fusion itself is not detrimental to the inhibitory activity of syntaxin-1A ${ }^{1-243}$ (Fig. $1 F, G$ ).

These data demonstrate that syntaxin$1 \mathrm{~A}^{1-243}$ has to participate in a stable SNARE complex to inhibit exocytosis but that the SNARE complex in itself is not inhibitory. This conclusion was confirmed by coexpression experiments with SNAP25. Similar to Munc18-1, SNAP-25 alone did not inhibit exocytosis but potently enhanced the inhibition of exocytosis by the shorter syntaxin-1A fragments or by open syntaxin-1A ${ }^{1-243}$ containing the LE mutation (Fig. $1 H$ ). Together, our results indicate that syntaxin-1 $\mathrm{A}^{1-243}$ inhibits exocytosis not by indirect sequestering of endogenous Munc18 and/or SNARE proteins but directly as a part of an inhibitory complex.

In vitro binding studies indicate that two Munc18/syntaxin$1 \mathrm{~A}^{1-243}$ complexes may exist in cells: a binary Munc18/syntaxin$1 \mathrm{~A}^{1-243}$ complex and a SNARE complex/Munc18 assembly containing syntaxin-1A ${ }^{1-243}$ (Dulubova et al., 1999, 2007; Shen et al., 2007). Which of these complexes is the inhibitory agent in exocytosis? It is difficult to envisage how binary the Munc18/syntaxin-1 $\mathrm{A}^{1-243}$ complex may inhibit exocytosis. On the other hand, SNARE complex/Munc18 assembly containing untethered syntaxin-1 $\mathrm{A}^{1-243}$ and endogenous vesicular SNARE proteins may block exocytosis by competing with endogenous membraneanchored syntaxins. The observation that coexpression of either Munc18-1 or SNAP-25 potentiates the inhibitory activity of various syntaxin-1A fragments (Fig. $1 B, C, H$ ) and that syntaxin-1A fragments are only inhibitory if capable of forming stable SNARE complexes (Fig. $1 E$ ) strongly argues that the heteromultimeric SNARE complex/Munc18 assembly is the inhibitory agent in exocytosis. The LE mutation that opens syntaxin-1 $\mathrm{A}^{1-243}$ and decreases formation of the binary Munc18-1/syntaxin-1A ${ }^{1-243}$ complex also decreases the ability of syntaxin- $1 \mathrm{~A}^{1-243}$ to inhibit exocytosis (Fig. 1C). This observation suggests that the binary Munc18-1/syntaxin-1A ${ }^{1-243}$ complex may not be inhibitory by itself but physiologically required as a precursor for subsequent formation of the inhibitory SNARE complex/Munc18 assembly.

\section{Critical role of the syntaxin-1A $\mathrm{N}$ terminus in the inhibition of exocytosis}

The data in Figure 1 suggest that syntaxin-1A ${ }^{1-243}$ inhibits exocytosis by a two-step pathway involving formation of the binary Munc18/syntaxin-1 complex and the heteromultimeric SNARE complex/Munc18 assembly. We considered our previous finding that formation of the SNARE complex/Munc18 assembly requires an intact, free $\mathrm{N}$-terminal sequence in syntaxin-1 (Dulubova et al., 2007). We thus examined whether changes in the $\mathrm{N}$
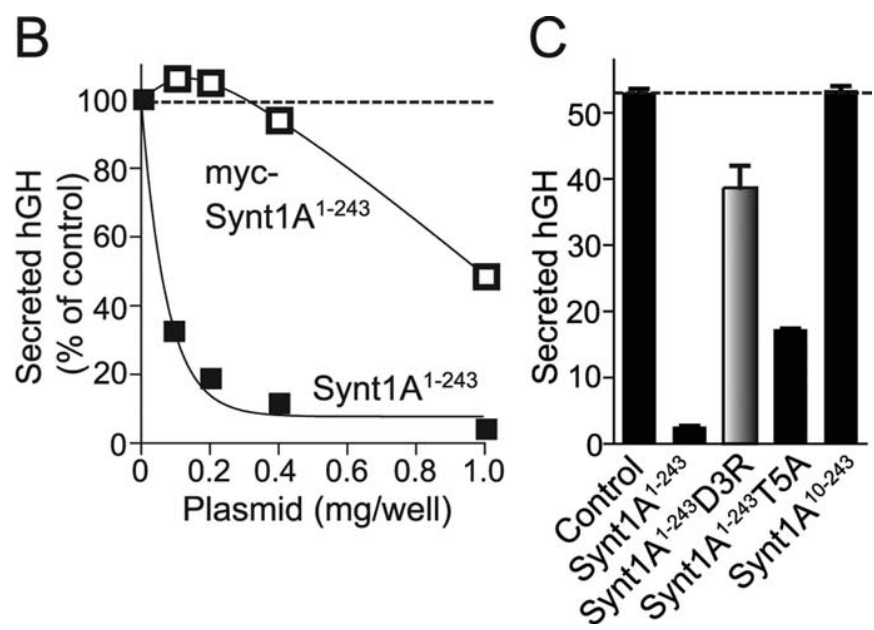

Figure 2. Free intact syntaxin-1A (Synt1A) $N$ terminus is required for the inhibition of exocytosis. $\boldsymbol{A}, \boldsymbol{B}$, Inactivation of the activity of syntaxin-1 $A^{1-243}$ by addition of an $\mathrm{N}$-terminal myc-tag. To ensure that the apparent effect of the myc-tag is transfected plasmid $(\boldsymbol{B})$. All samples contained equal amounts of total transfected DNA (1.05 $\mu \mathrm{g} /$ well), with the remainder made up of empty expression vector. $\boldsymbol{C}$, Mutations in, or truncation of, the $\mathrm{N}$ terminus of syntaxin-1A inactivate the inhibition of constitutive exocytosis by syntaxin-1 $A^{1-243}$. All data shown are from a representative experiment performed in duplicate and independently repeated at least twice with comparable results. Error bars indicate SEM.

terminus of syntaxin-1 $\mathrm{A}^{1-243}$ diminished its inhibition of exocytosis.

Strikingly, addition of a short myc-epitope tag to the syntaxin-1 $\mathrm{N}$ terminus inactivated the inhibitory activity of syntaxin-1A $\mathrm{A}^{1-243}$ (Fig. 2A). This effect was not attributable to a decrease in protein concentration, because immunoblots confirmed that syntaxin-1 $\mathrm{A}^{1-243}$ and myc-syntaxin-1 $\mathrm{A}^{1-243}$ were present at comparable levels (data not shown). Moreover, increasing the amount of transfected DNA to enhance protein expression revealed that relatively low levels of syntaxin-1 $\mathrm{A}^{1-243}$ potently inhibited exocytosis, whereas even at 10-fold higher concentrations, myc-tagged syntaxin-1 $\mathrm{A}^{1-243}$ was ineffective (Fig. $2 B$ ).

The $\mathrm{N}$ termini of plasma-membrane syntaxins are composed of a conserved sequence that precedes the $\mathrm{H}_{\mathrm{abc}}$ domain (Fig. $1 \mathrm{~A}$ ). To test the role of the conserved $\mathrm{N}$-terminal syntaxin-1 sequence, we examined whether substitutions in two conserved amino acids (D3R and T5A) or a short N-terminal truncation (deletion of residues 2-9) alter the inhibitory effect of syntaxin-1 $\mathrm{A}^{1-243}$. These mutations were chosen because similar substitutions disrupt binding of SM proteins to syntaxin -5 and -16 , which bind to their cognate SM proteins via an $\mathrm{N}$-terminal interaction ( $\mathrm{Du}$ lubova et al., 2002; Yamaguchi et al., 2002). Strikingly, the $\mathrm{N}$-terminal deletion and the D3R substitution nearly abolished the inhibitory action of syntaxin-1 $\mathrm{A}^{1-243}$, and the T5A substitution severely decreased it (Fig. 2C).

\section{General involvement of the N-terminal sequence of plasma-} membrane syntaxins in exocytosis

Syntaxin-1 is not normally expressed in non-neuronal cells such as HEK293 cells and HeLa cells, which likely contain syntaxin-2, -3 , and/or -4 . To probe whether the effect of syntaxin-1A in HEK293 and HeLa cells reflects a general function of plasmamembrane syntaxins in exocytosis, we investigated whether cytoplasmic fragments of syntaxin-2, -3 and -4 that correspond to syntaxin-1 $\mathrm{A}^{1-243}$ inhibit constitutive exocytosis. Expressed alone, syntaxin-2 $2^{1-243}$ and syntaxin- $4^{1-251}$ moderately inhibited exocytosis, whereas syntaxin- $3^{1-242}$ had no effect (Fig. $3 A$ ). Co- 
A

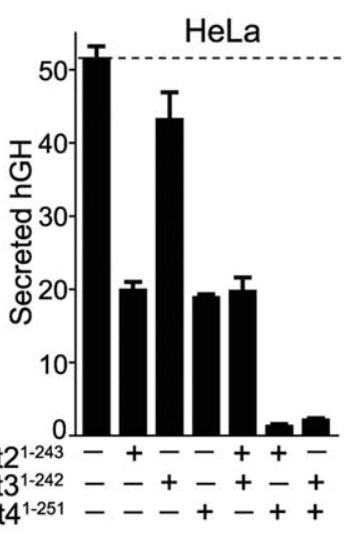

C

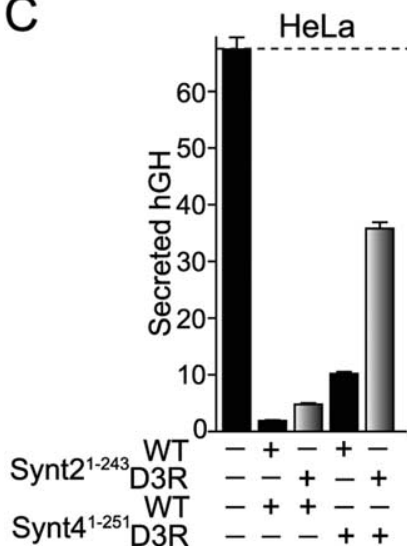

B

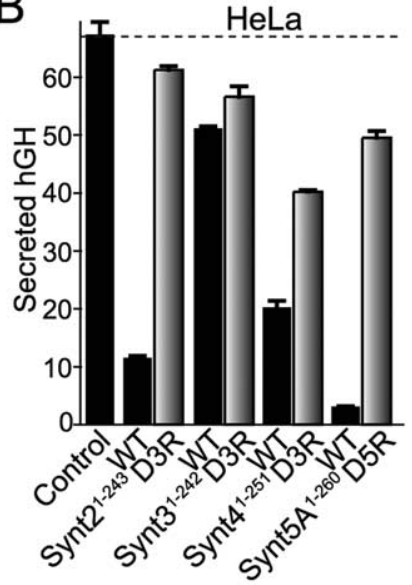

D

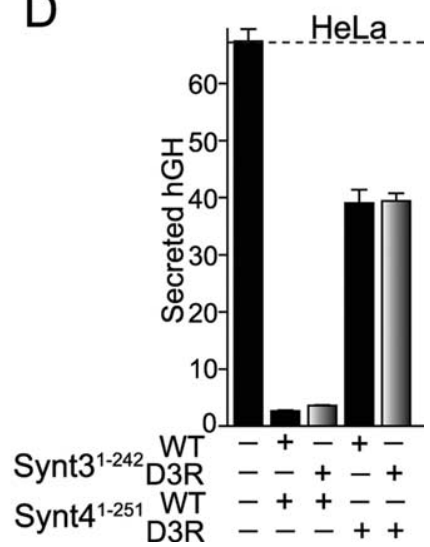

Figure 3. Effects of plasma membrane syntaxins $2-4$ and Golgi syntaxin-5A on constitutive exocytosis also depends on $\mathrm{N}$-terminal sequences. Secretion assays were performed as described in Figure 1. Syntaxin (Synt)-2, $-3,-4$, and -5A fragments were modeled after the syntaxin-1 $A^{1-243}$ fragment based on protein sequence alignment. $A$, Effects of individual syntaxins and their combinations. $\boldsymbol{B}$, Comparison of effects of syntaxins with or without the D3R mutation (D5R for syntaxin-5A). C, D, Unequal contributions of syntaxins to constitutive exocytosis inhibition by introducing D3R mutations in various combinations of syntaxins- 2 and $-4(C)$ and syntaxins-3 and $-4(\boldsymbol{D})$. All data shown are from a representative experiment performed in duplicate and independently repeated at least twice with comparable results. Error bars indicate SEM. WT, Wild type.

expression of either syntaxin- $2^{1-243}$ or syntaxin- $3^{1-242}$ with syntaxin- $4^{1-251}$, however, produced strong inhibition of exocytosis (Fig. $3 A$ ).

We next tested whether the D3R substitution that inactivates the inhibitory effect of syntaxin-1 $\mathrm{A}^{1-243}$ also abolishes the inhibitory effect of other plasma membrane syntaxins. Indeed, the D3R substitution blocked the moderate inhibition of exocytosis mediated by syntaxin-2 and -4 (Fig. $3 B$ ). Again, as a positive control, we used Golgi-resident syntaxin-5A in which the corresponding D5R mutation that disrupts binding to Sly I (Yamaguchi et al., 2002; Dulubova et al., 2003) also reversed the indirect inhibition of constitutive exocytosis (Fig. $3 B$ ). Moreover, the D3R substitution strongly decreased the inhibitory effect of coexpressed syntaxin-2/-4 and syntaxin-3/-4 fragments (Fig. $3 C, D)$. Overall, these data suggest a general involvement of the $\mathrm{N}$-terminal sequence of plasma membrane syntaxins in exocytosis, possibly by a universal mechanism that involves binding of SM protein to SNARE complexes.
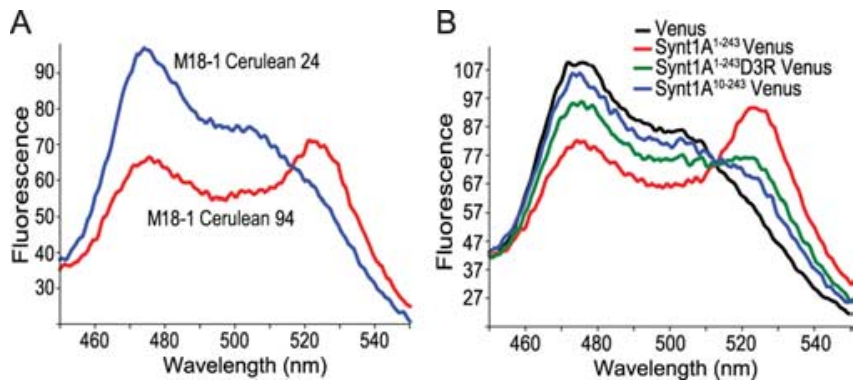

Figure 4. FRET reveals essential role of the N-terminal syntaxin-1A sequence in Munc18-1 binding. $\boldsymbol{A}$, Venus-tagged syntaxin-1A ${ }^{1-243}$ exhibits efficient FRET when bound to Munc18-1 containing monomeric Cerulean inserted at position 94 but not at position 24. Fluorescence emission spectra (excitation, $433 \mathrm{~nm}$ ) were collected from HEK293 cells transfected with expression vectors encoding Venus-tagged syntaxin-1A ${ }^{1-243}$ and Cerulean-tagged Munc18-1. $\boldsymbol{B}$, Intact $N$ terminus of syntaxin-1A (Synt1A) is required for efficient FRET with Munc18-1. HEK293 cells were transfected with Munc18-1 (94, Venus GFP, or various syntaxin-1A fragments fused to Venus. Cell extracts were mixed so that each sample contained an equal amount of Cerulean (excitation, $433 \mathrm{~nm}$; emission, $475 \mathrm{~nm}$ ) and Venus (excitation, $515 \mathrm{~nm}$; emission, $528 \mathrm{~nm}$ ) fluorescence. After incubation to allow formation of Munc18-1/syntaxin-1A complexes, fluorescence emission spectra (excitation, $433 \mathrm{~nm}$ ) were collected. Data are from a single experiment repeated multiple times with similar results.

\section{The $\mathrm{N}$ terminus of syntaxin-1A directly interacts with Munc18-1: FRET analysis}

Our secretion assays suggest that soluble syntaxin-1A fragments may universally inhibit exocytosis by initially forming the binary complex with Munc18 that is then converted into the inhibitory SNARE complex/Munc18 assembly. This mechanism requires coupling of the two Munc18/syntaxin-1 binding modes, possibly through a shared structural feature. One potential connection between two binding modes could be provided by the $\mathrm{N}$ terminus of syntaxin-1 because it is required for the SNARE complex/ Munc18 assembly (Dulubova et al., 2007) and the N-terminal sequences in other syntaxins are known to participate in SM protein binding. Although immunoprecipitations and affinity measurements confirmed the long-held conclusion that the $\mathrm{N}$ terminus of syntaxin- 1 is dispensable for the formation of a binary Munc18-1/syntaxin-1A complex in the presence or absence of the LE mutation (supplemental Figs. 2, 5 and supplemental Table 1 , available at www.jneurosci.org as supplemental material), it is possible that the syntaxin- $1 \mathrm{~N}$ terminus makes a contribution to this interaction and that this contribution was masked by the high affinity of the complex. To examine this possibility, we developed a FRET-based assay for syntaxin-1A binding to Munc18-1 and used monomeric Venus and Cerulean as green fluorescent protein (GFP) variants because of their excellent FRET properties (Nagai et al., 2002; Rizzo et al., 2004).

We fused Venus to the $\mathrm{C}$ terminus of syntaxin-1A ${ }^{1-243}$ (which, as we showed above, does not impair its inhibitory effect) (Fig. $1 F, G$ ), and inserted Cerulean into Munc18-1 at two positions, after residues 24 and 94. Rescue experiments with Munc18-1 knock-out neurons revealed that insertions of Cerulean at these two positions do not impair Munc18-1 function (F. Deak and T. C. Südhof, unpublished observation). When we coexpressed Cerulean-tagged Munc18-1 with Venus-tagged syntaxin-1A ${ }^{1-243}$ in transfected cells, we observed low FRET efficiency when Cerulean was inserted at position 24 of Munc18-1 but high FRET efficiency when Cerulean was inserted at position 94 (Fig. 4A). Next, we separately produced in transfected cells Venus-tagged syntaxin-1 $\mathrm{A}^{1-243}$, syntaxin-1 $\mathrm{A}^{1-243} \mathrm{D} 3 \mathrm{R}$, and syntaxin-1A ${ }^{10-243}$; Venus alone; and Cerulean-tagged Munc18-1. We then bound the Venus-tagged syntaxins to Cerulean-tagged 
Munc18-1, such that each sample initially exhibited the same Venus and Cerulean fluorescence. Incubation of Ceruleantagged Munc18-1 with Venus-tagged syntaxin-1 $\mathrm{A}^{1-243}$ resulted in strong FRET, whereas incubation of Cerulean-tagged Munc18-1 with Venus-tagged syntaxin$1 \mathrm{~A}^{1-243} \mathrm{D} 3 \mathrm{R}$ or syntaxin-1A $\mathrm{A}^{10-243}$ produced almost no FRET, suggesting that the FRET depends on the N-terminal syntaxin-1 $\mathrm{A}^{1-243}$ sequence, although the high-affinity binding does not (Fig. 4B; and supplemental Table 1 and supplemental Figs. 2, 5, available at www.jneurosci. org as supplemental material). All recorded spectra intersected at the isosbestic point, confirming equal concentrations of fluorophores present in each sample. These data are consistent with the notion that the syntaxin-1A $\mathrm{N}$ terminus participates in the binary syntaxin-1A/Munc18-1 complex in a manner that does not significantly contribute to its overall affinity but instead induces a subtle conformational change in the complex. Although other interpretations of these data are possible, this notion accounts for the large changes we observed in FRET, which is extremely sensitive to small changes in orientation and distance between the two fluorescent probes.

The $\mathrm{N}$ terminus of syntaxin-1A directly interacts with Munc18-1: NMR analysis We next examined the Munc18-1/ syntaxin-1A interaction by NMR spectroscopy. First, we compared ${ }^{1} \mathrm{H}-{ }^{15} \mathrm{~N}$ HSQC spectra of a uniformly ${ }^{15} \mathrm{~N}$-labeled syntaxin-1 $\mathrm{A}^{2-243}$ fragment in the absence and presence of Munc18-1. The spectrum of isolated syntaxin-1 $\mathrm{A}^{2-243}$ (Fig. 5A, black contours) is characterized by broad crosspeaks corresponding to the structured part of the molecule (residues 27-217; X. Chen and J. Rizo, unpublished results) and sharp cross-peaks from the remaining sequences, which are highly flexible (note the abundance of strong cross-peaks with poor dispersion in the ${ }^{1} \mathrm{H}$ dimension). The addition of Munc18-1 led to broadening beyond detection of most cross-peaks (Fig. $5 A$, red contours), as expected from the participation of most of the syntaxin- $1 \mathrm{~A}^{2-243}$ sequence in binding to Munc18-1. Interestingly, broadening beyond detection was also observed for the cross-peaks corresponding to Thr 5 and Thr10 from the $\mathrm{N}$-terminal syntaxin-1A sequence, suggesting a direct interaction (Fig. 5A). Examination of the crystal structure of the Munc18-1/syntaxin-1A complex showed that the N-terminal sequence of syntaxin-1A could easily reach the same binding site of Munc18-1 that is involved in binding of Sly1 to the syntaxin-5/ Sed5p N-terminal sequence (Bracher and Weissenhorn, 2002; Dulubova et al., 2003) (Fig. 5D, dashed line).

Munc18-1 and other SM proteins contain three domains, of which the $\mathrm{N}$-terminal domain is autonomously folded ( $\mathrm{Du}$ lubova et al., 2003). In Sly1, the N-terminal domain is responsible for binding to the short $\mathrm{N}$-terminal sequence of syntaxin-5
(Bracher and Weissenhorn, 2002; Dulubova et al., 2003; Arac et al., 2005). To test whether the interaction of Munc18-1 with the $\mathrm{N}$ terminus of syntaxin-1A may operate by a similar mechanism, we analyzed ${ }^{1} \mathrm{H}_{-}{ }^{15} \mathrm{~N}$ HSQC spectra of syntaxin-1 $\mathrm{A}^{2-180}$ (which lacks the SNARE motif and does not form a closed conformation) in the presence and absence of the Munc18-1 N-terminal domain (residues 1-136). These two fragments do not exhibit a detectable interaction in GST pulldown or gel-filtration experiments (data not shown), suggesting that they do not form a stable complex. However, we observed broadening and/or shift of numerous cross-peaks from ${ }^{15} \mathrm{~N}$-labeled syntaxin-1 $\mathrm{A}^{2-180}$ after addition of Munc18-1 ${ }^{1-136}$ (Fig. 5B,C). This observation reveals a direct interaction between these protein fragments at the high concentrations used to acquire the NMR spectra $(50 \mu \mathrm{M})$. Remarkably, the sharp cross-peaks from Thr5 and Thr10 are broadened beyond detection after binding to Munc18-1 ${ }^{1-136}$, demonstrating that the $\mathrm{N}$-terminal sequence of syntaxin-1 $\mathrm{A}^{2-180}$ participates in this interaction. Moreover, the cross-peaks from the $\mathrm{H}_{\mathrm{abc}}$ domain that exhibit the most substantial perturbations after binding to Munc18-1 ${ }^{1-136}$ correspond to the region of the $\mathrm{H}_{\mathrm{abc}}$ domain that 


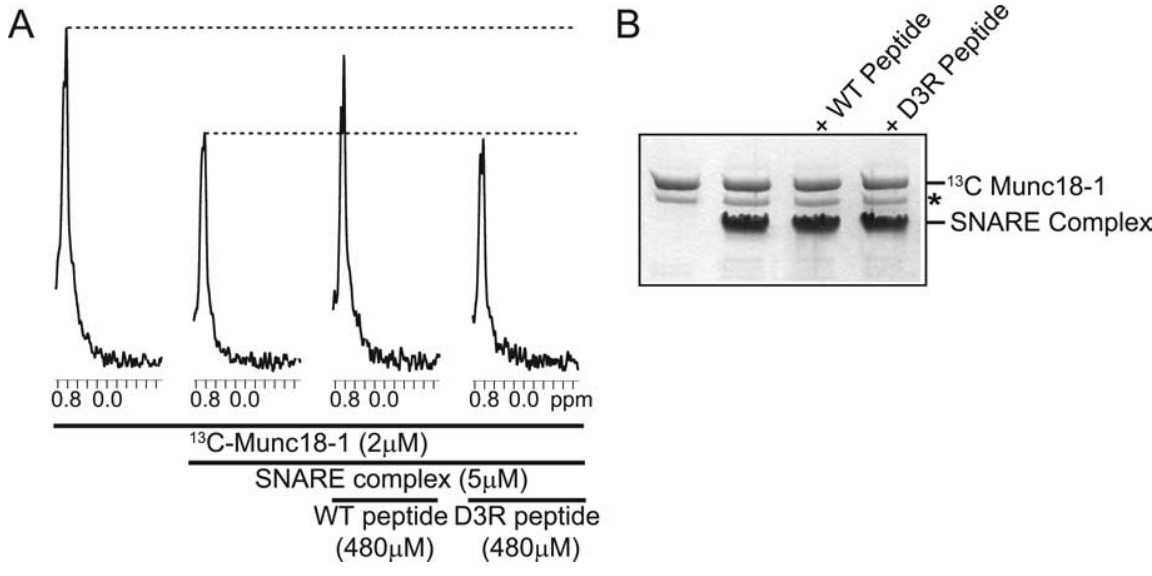

Figure 6. Wild-type (WT) but not mutant (D3R) N-terminal syntaxin-1A peptide interferes with Munc18-1/SNARE complex assembly. $\boldsymbol{A}, 1{ }^{13} \mathrm{C}$-edited ${ }^{1} \mathrm{H}$-NMR spectra of $2 \mu \mathrm{m}{ }^{13} \mathrm{C}$-labeled Munc18-1 in the absence or presence of $5 \mu \mathrm{m}$ unlabeled preassembled SNARE complex containing syntaxin-1A ${ }^{2-253}$, Synaptobrevin $2^{1-96}$, and the two SNARE motifs of SNAP- 25 (residues 11-82 and 141-203), before and after addition of $480 \mu \mathrm{m}$ wild-type or D3R mutant syntaxin-1A N-terminal peptides (residues 2-16 with addition of a (-terminal cysteine residue). B, SDS-PAGE analysis of protein complexes used in NMR experiments shown in $\boldsymbol{A}$. The asterisk indicates a proteolytic fragment of Munc18-1; such proteolysis occurs in a flexible loop and does not impair binding to syntaxin-1A (Misura et al., 2000) or the SNARE complex (our unpublished results).

binds to the Munc18-1 N-terminal domain in the crystal structure of the Munc18-1/syntaxin-1A complex (Fig. 5D), which indicates that the weak interaction observed in our NMR experiments reproduces the binding mode observed in the crystal structure. Overall, these experiments show that the N-terminal sequence of syntaxin-1A directly binds to Munc18-1 and suggest that this sequence together with the $\mathrm{N}$-terminal $\mathrm{H}_{\mathrm{abc}}$ domain participates in a low-affinity interaction with Munc18-1 both in the open and the closed conformation of syntaxin-1A, although its energetic contribution is not required for the stability of the Munc18-1 complex with the closed conformation of syntaxin-1A.

\section{Binding of Munc18-1 by the syntaxin-1A $\mathrm{N}$ terminus is essential for synaptic vesicle exocytosis}

To test the importance of the syntaxin-1A N terminus in synaptic vesicle exocytosis, we sought to perturb the $\mathrm{N}$ terminusdependent interaction of syntaxin-1A and Munc18-1 by using a short peptide containing the first 15 aa residues of syntaxin-1A. As a negative control, we chose a peptide carrying the D3R substitution because this mutation universally inactivated the inhibition of exocytosis by various syntaxin fragments (Figs. 2, 3) and led to dramatically reduced FRET with fluorescent Munc18-1 (Fig. 4B). Because tight binding of syntaxin-1A to Munc18-1 does not require the syntaxin-1A $\mathrm{N}$ terminus (supplemental Fig. 2 , available at www.jneurosci.org as supplemental material), the peptide is not expected to displace syntaxin-1A from its binary complex with Munc18-1. However, the peptide could compete with the SNARE complex for Munc18-1 binding, because this interaction critically depends on the syntaxin-1A $\mathrm{N}$ terminus (Dulubova et al., 2007). To test the latter prediction, we used a previously described 1D NMR method (Arac et al., 2003). As observed previously (Dulubova et al., 2007), the intensity of the strongest methyl resonance (SMR) in the $1 \mathrm{D}{ }^{13} \mathrm{C}$-edited ${ }^{1} \mathrm{H}$ NMR spectrum of ${ }^{13}$ C-labeled Munc18-1 was substantially decreased after the addition of excess unlabeled SNARE complex because of quantitative formation of the Munc18-1/SNARE complex assembly (Fig. 6A). In a parallel experiment in which $480 \mu \mathrm{M}$ wild-type peptide was added, the SMR intensity of ${ }^{13} \mathrm{C}$ - labeled Munc18-1 was almost restored to that of isolated Munc18-1, showing that peptide binding to Munc18-1 displaced the SNARE complex almost completely; in contrast, the D3R mutant peptide had no significant effect (Fig. 6A). SDS-PAGE analysis of the samples used for the NMR measurements confirmed equal amounts of all proteins and full assembly of the SNARE complexes (Fig. 6B). These results show that the wild-type peptide competes with the SNARE complex for binding to Munc18-1 and that the D3R mutation abolishes this activity. The considerable excess of peptide required for the competition reflects its weaker affinity for Munc18-1 compared with the SNARE complex. Note that we were previously unable to detect binding of the wild-type peptide to the isolated $\mathrm{N}$-terminal domain of Munc18-1 (Dulubova et al., 2003), which likely arises because domain 2 of SM proteins cooperates with the N-terminal domain to bind to their cognate syntaxin N-terminal peptides (Bracher and Weissenhorn, 2002; Hu et al., 2007).

To test the effects of the peptides in a physiological system, we took advantage of the high electrophysiological resolution and accessibility offered by the large nerve terminals in the calyx of Held synapse (Schneggenburger and Forsythe, 2006). We introduced into the presynaptic terminal the wild-type peptide that corresponds to the $\mathrm{N}$ terminus of syntaxin-1A, again using the D3R substitution peptide as a negative control (Fig. 7). The wildtype peptide strongly inhibited exocytosis in a time-dependent manner, presumably reflecting the time it takes for the peptide to diffuse into the nerve terminal (Fig. 7A). Inhibition of exocytosis by the wild-type peptide was observed at relatively low peptide concentrations in the pipette $(0.25 \mathrm{~mm})$ and was almost complete after $\sim 20 \mathrm{~min}$ at $1 \mathrm{~mm}$ (Fig. $7 C$ ). In contrast, even high concentrations of the D3R-mutant peptide had no measurable effect on exocytosis (Fig. $7 B$ ). Neither peptide had altered $\mathrm{Ca}^{2+}$ currents in the terminal (Fig. $7 A, B$ ), indicating that the peptides did not interfere with the channel function, or adversely affected the integrity of the terminal.

\section{Discussion}

At the synapse, Munc18-1 and the SNARE proteins syntaxin-1, SNAP-25, and synaptobrevin/VAMP are thought to constitute the core of the fusion machinery (Jahn et al., 2003; Brunger, 2005; Rizo et al., 2006). Munc18-1 interacts with SNARE proteins in two distinct modes: the long-recognized binding to syntaxin-1 in the binary complex in which syntaxin-1 is folded into a closed conformation, and the recently observed binding to assembled SNARE complexes containing syntaxin-1 in an open conformation (Dulubova et al., 2007; Rickman et al., 2007; Shen et al., 2007). However, previous studies did not detect a connection between the two Munc18/ SNARE interaction modes, and their significance for the fundamental function of Munc18-1 in fusion remained unknown.

We now demonstrate that although the binding of Munc18-1 to closed syntaxin-1 does not require the syntaxin- $1 \mathrm{~N}$ terminus, it nevertheless involves a direct interaction of the syntaxin-1 $\mathrm{N}$ terminus with Munc18-1 similar to the binding of assembled SNARE complexes to Munc18-1 (Figs. 4, 5). 
A WT peptide (0.5 mM) -2 min after break-in -25 min after break-in

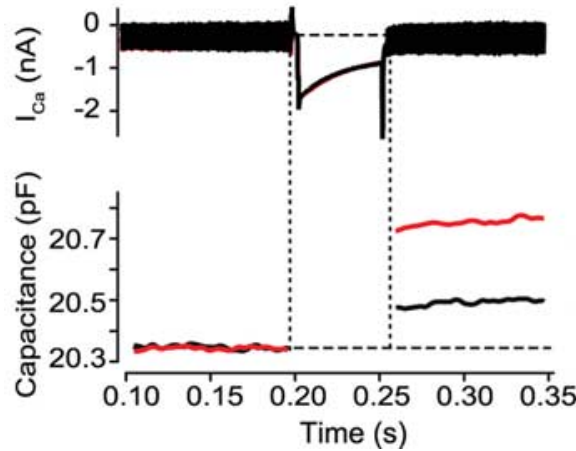

B

B $\quad$ 3R peptide $(0.5 \mathrm{mM})$ -2 min after break-in -30 min after break-in
C

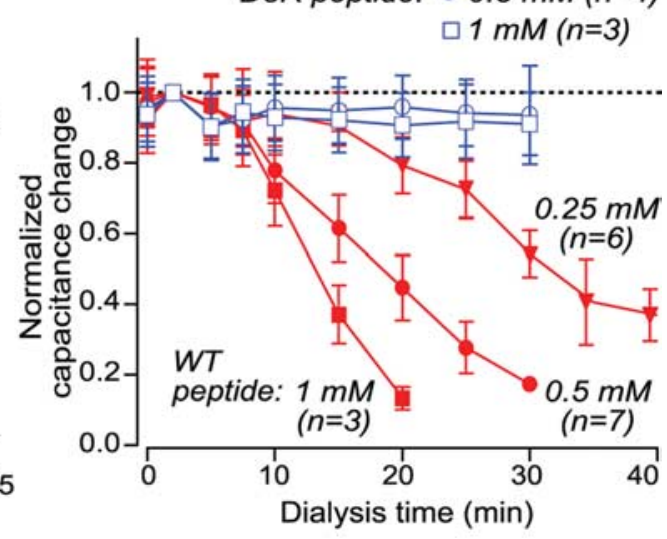

Figure 7. Effect of N-terminal syntaxin-1A peptides on synaptic vesicle exocytosis in the calyx of Held synapse. $A, B$, Sample traces of calcium current and capacitance measurements at the presynaptic terminal of calyx of Held performed after dialysis of $0.5 \mathrm{~mm}$ wild-type syntaxin-1A peptide $(\boldsymbol{A})$ and $0.5 \mathrm{~mm}$ D3R syntaxin-1A peptide $(\boldsymbol{B})$. C, Dose-dependent rundown of exocytosis after dialysis of wild-type or D3R syntaxin-1A peptides. WT, Wild type; $n$, number of independent experiments.

We than asked whether Munc18-1 binding to the $\mathrm{N}$ terminus of syntaxin-1 is functionally important. Using two different approaches, we show that the binding of the syntaxin- $1 \mathrm{~N}$ terminus to Munc18-1 is essential for fusion and is likely required for Munc18-1 function via both interaction modes. Moreover, our results indicate that the mechanism thus uncovered applies to all forms of exocytosis.

Our peptide injection experiments into calyx terminals revealed that a wild-type peptide corresponding to the free $\mathrm{N}$ terminus of syntaxin-1 blocked exocytic fusion, whereas a mutant peptide with a single amino acid substitution had no effect (Fig. 7 ). The wild-type peptide but not the mutant peptide perturbed Munc18-1 binding to assembled SNARE complexes in the 1D NMR experiments (Fig. 6). This experiment demonstrates the importance of the binding of the syntaxin-1 $\mathrm{N}$ terminus to Munc18-1 in a physiologically relevant system and suggests that Munc18-1 interaction with SNARE complexes is essential. Because of the small overall contribution of the syntaxin- $1 \mathrm{~N}$ terminus to the stability of the binary Munc18-1/syntaxin-1 complex (supplemental Fig. 2 and supplemental Table 1, available at www. jneurosci.org as supplemental material), it seems unlikely that the peptides used in this study interfered with the binary complex, and we therefore cannot make any conclusions about the functional importance of this complex.

Our transfection experiments demonstrate that the previously described inhibitory effect of syntaxin-1A ${ }^{1-243}$ in exocytosis (Khvotchev and Sudhof, 2004) acts by binding of syntaxin-1 to Munc18 proteins and its incorporation into SNARE complexes and that this inhibitory effect requires the intact free syntaxin- $1 \mathrm{~N}$ terminus (Figs. 1, 2). In addition, these experiments showed that truncated versions of other plasma syntaxins also inhibit exocytosis and that their $\mathrm{N}$-terminal sequences are similarly required for inhibition (Fig. 3), a result that generalizes our conclusions to all forms of exocytosis. The fact that the LE mutation, which opens syntaxin-1 and promotes SNARE complex formation (Dulubova et al., 1999) (supplemental Fig. 1, available at www. jneurosci.org as supplemental material), also diminishes the inhibitory action of the syntaxin- $1^{1-243}$ on regulated and constitutive exocytosis indicates that binding of Munc18-1 to the closed syntaxin-1 may also be required. However, at present we cannot exclude the possibility that the LE mutation inhibits the formation of the SNARE complex/Munc18 assembly and thereby de- creases the inhibitory activity of truncated syntaxins, but we consider this possibility unlikely because our biochemical data indicate that any effect of the LE mutation on the SNARE complex/Munc18 assembly is, at best, subtle. Thus, truncated syntaxin-1 $\mathrm{A}^{1-243}$ likely inhibits exocytosis by a two-step reaction during which it first forms the high-affinity binary complex with Munc18; this binary complex is then converted into the SNARE complex/Munc18 assembly, which most likely represents the actual inhibitory agent.

Viewed together, our results are consistent with a general model whereby during exocytic membrane fusion, Munc18-1 initially binds to closed syntaxin before SNARE complex assembly. The model indicates that during the subsequent assembly of syntaxin-1 into SNARE complexes with SNAP-25 and synaptobrevin, Munc18-1 remains associated with syntaxin-1, at least in part, via its $\mathrm{N}$-terminal sequence. Our data strongly suggest that the interaction of Munc18-1 with the syntaxin-1 $\mathrm{N}$ terminus is essential for fusion and are consistent with a critical role of the SNARE complex/Munc18 assembly in fusion, but do not prove such a role, nor do they provide evidence for an essential role of the binary Munc18/syntaxin complex in fusion. Moreover, our data do not identify the precise function of the SNARE complex/ Munc18 assembly in fusion, issues that remain to be addressed in future studies.

Can our observations shed light on the universal functions of SM proteins? A plausible view is that the molecular machinery responsible for membrane traffic is partly conserved to perform the basic reactions underlying membrane fusion and fission and is partly cell type and compartment specific to meet the unique requirements of a particular cellular locale. SM proteins are conserved in fusion and universally appear to bind to SNARE complexes. Our data are consistent with the notion that for most, possibly all, SM proteins, this binding is nucleated by an interaction of the SM protein with the free syntaxin $\mathrm{N}$ terminus, as initially observed for Sly1 and Vps45 (Dulubova et al., 2002, 2003; Yamaguchi et al., 2002). It remains to be established whether this interaction serves to promote and catalyze SNARE complex assembly to convert nonproductive SNARE complexes into productive SNARE complexes, or whether it serves to allow an action of the SM proteins on membranes containing assembled SNARE complexes (Jahn et al., 2003; Rizo et al., 2006; Shen et al., 2007). At the same time, SM proteins illustrate how a general fusion 
protein adapts to a particular cellular locale, because every SM protein appears to exhibit a unique site-specific set of features in its interaction with its cognate SNARE proteins. The Munc18-1/ syntaxin-1 interaction serves as an example of this conclusion because it involves two mechanistically different modes of interaction which are coupled by a common binding to the free $\mathrm{N}$ terminus of syntaxin-1. The function of the Munc18/syntaxin heterodimer, the regulation of its transition into the SNARE complex/Munc18 assembly, and the need for Munc18 in fusion are important issues that remain to be addressed to fully understand the role of Munc18 in neurotransmitter release.

\section{References}

Arac D, Murphy T, Rizo J (2003) Facile detection of protein-protein interactions by one-dimensional NMR spectroscopy. Biochemistry 42:2774-2780.

Arac D, Dulubova I, Pei J, Huryeva I, Grishin NV, Rizo J (2005) Threedimensional structure of the rSlyl $\mathrm{N}$-terminal domain reveals a conformational change induced by binding to syntaxin 5. J Mol Biol 346:589-601.

Borst JG, Helmchen F, Sakmann B (1995) Pre- and postsynaptic whole-cell recordings in the medial nucleus of the trapezoid body of the rat. J Physiol (Lond) 489:825-840.

Bracher A, Weissenhorn W (2001) Crystal structures of neuronal squid Sec1 implicate inter-domain hinge movement in the release of t-SNAREs. J Mol Biol 306:7-13.

Bracher A, Weissenhorn W (2002) Structural basis for the Golgi membrane recruitment of Slylp by Sed5p. EMBO J 21:6114-6124.

Brunger AT (2005) Structure and function of SNARE and SNAREinteracting proteins. Q Rev Biophys 38:1-47.

Carpp LN, Ciufo LF, Shanks SG, Boyd A, Bryant NJ (2006) The Seclp/ Munc18 protein Vps45p binds its cognate SNARE proteins via two distinct modes. J Cell Biol 173:927-936.

Carr CM, Grote E, Munson M, Hughson FM, Novick PJ (1999) Seclp binds to SNARE complexes and concentrates at sites of secretion. J Cell Biol 146:333-344.

Delaglio F, Grzesiek S, Vuister GW, Zhu G, Pfeifer J, Bax A (1995) NMRPipe: a multidimensional spectral processing system based on UNIX pipes. J Biomol NMR 6:277-293.

Dulubova I, Sugita S, Hill S, Hosaka M, Fernandez I, Sudhof TC, Rizo J (1999) A conformational switch in syntaxin during exocytosis: role of munc18. EMBO J 18:4372-4382.

Dulubova I, Yamaguchi T, Gao Y, Min SW, Huryeva I, Sudhof TC, Rizo J (2002) How Tlg2p/syntaxin 16 "snares" Vps45. EMBO J 21:3620-3631.

Dulubova I, Yamaguchi T, Arac D, Li H, Huryeva I, Min SW, Rizo J, Sudhof TC (2003) Convergence and divergence in the mechanism of SNARE binding by Sec1/Munc18-like proteins. Proc Natl Acad Sci USA 100:32-37.

Dulubova I, Khvotchev M, Liu S, Huryeva I, Sudhof TC, Rizo J (2007) Munc18-1 binds directly to the neuronal SNARE complex. Proc Natl Acad Sci USA 104:2697-2702.

Fasshauer D, Antonin W, Margittai M, Pabst S, Jahn R (1999) Mixed and non-cognate SNARE complexes. Characterization of assembly and biophysical properties. J Biol Chem 274:15440-15446.

Fernandez I, Ubach J, Dulubova I, Zhang X, Sudhof TC, Rizo J (1998) Three-dimensional structure of an evolutionarily conserved $\mathrm{N}$-terminal domain of syntaxin 1A. Cell 94:841-849.

Hakes DJ, Dixon JE (1992) New vectors for high level expression of recombinant proteins in bacteria. Anal Biochem 202:293-298.

Hu SH, Latham CF, Gee CL, James DE, Martin JL (2007) Structure of the Munc18c/Syntaxin4 N-peptide complex defines universal features of the N-peptide binding mode of Sec1/Munc18 proteins. Proc Natl Acad Sci USA 104:8773-8778.
Jahn R, Scheller RH (2006) SNAREs-engines for membrane fusion. Nat Rev Mol Cell Biol 7:631-643.

Jahn R, Lang T, Sudhof TC (2003) Membrane fusion. Cell 112:519-533.

Johnson BA, Blevins RA (1994) NMRView: a computer program for the visualization and analysis of NMR data. J Biomol NMR 4:603-614.

Khvotchev M, Sudhof TC (2004) Proteolytic processing of amyloid-beta precursor protein by secretases does not require cell surface transport. J Biol Chem 279:47101-47108.

Khvotchev MV, Ren M, Takamori S, Jahn R, Sudhof TC (2003) Divergent functions of neuronal Rab11b in Ca2 ${ }^{+}$-regulated versus constitutive exocytosis. J Neurosci 23:10531-10539.

Latham CF, Lopez JA, Hu SH, Gee CL, Westbury E, Blair DH, Armishaw CJ, Alewood PF, Bryant NJ, James DE, Martin JL (2006) Molecular dissection of the Munc18c/syntaxin 4 interaction: implications for regulation of membrane trafficking. Traffic 7:1408-1419.

Matos MF, Mukherjee K, Chen X, Rizo J, Sudhof TC (2003) Evidence for SNARE zippering during Ca2+-triggered exocytosis in PC12 cells. Neuropharmacology 45:777-786.

Misura KM, Scheller RH, Weis WI (2000) Three-dimensional structure of the neuronal-Sec1-syntaxin 1a complex. Nature 404:355-362.

Nagai T, Ibata K, Park ES, Kubota M, Mikoshiba K, Miyawaki A (2002) A variant of yellow fluorescent protein with fast and efficient maturation for cell-biological applications. Nat Biotechnol 20:87-90.

Rickman C, Medine CN, Bergmann A, Duncan RR (2007) Functionally and Spatially Distinct Modes of munc18-Syntaxin 1 Interaction. J Biol Chem 282:12097-12103.

Rizo J, Sudhof TC (2002) Snares and Munc18 in synaptic vesicle fusion. Nat Rev Neurosci 3:641-653.

Rizo J, Chen X, Arac D (2006) Unraveling the mechanisms of synaptotagmin and SNARE function in neurotransmitter release. Trends Cell Biol 16:339-350.

Rizzo MA, Springer GH, Granada B, Piston DW (2004) An improved cyan fluorescent protein variant useful for FRET. Nat Biotechnol 22:445-449.

Schneggenburger R, Forsythe ID (2006) The calyx of Held. Cell Tissue Res 326:311-337.

Schoch S, Deak F, Konigstorfer A, Mozhayeva M, Sara Y, Sudhof TC, Kavalali ET (2001) SNARE function analyzed in synaptobrevin/VAMP knockout mice. Science 294:1117-1122.

Shen J, Tareste DC, Paumet F, Rothman JE, Melia TJ (2007) Selective activation of cognate SNAREpins by Sec1/Munc18 proteins. Cell 128:183-195.

Sutton RB, Fasshauer D, Jahn R, Brunger AT (1998) Crystal structure of a SNARE complex involved in synaptic exocytosis at $2.4 \mathrm{~A}$ resolution. $\mathrm{Na}-$ ture 395:347-353.

Togneri J, Cheng YS, Munson M, Hughson FM, Carr CM (2006) Specific SNARE complex binding mode of the Sec1/Munc-18 protein, Seclp. Proc Natl Acad Sci USA 103: 17730-17735.

Verhage M, Maia AS, Plomp JJ, Brussaard AB, Heeroma JH, Vermeer H, Toonen RF, Hammer RE, van den Berg TK, Missler M, Geuze HJ, Sudhof TC (2000) Synaptic assembly of the brain in the absence of neurotransmitter secretion. Science 287:864-869.

Washbourne P, Thompson PM, Carta M, Costa ET, Mathews JR, LopezBendito G, Molnar Z, Becher MW, Valenzuela CF, Partridge LD, Wilson MC (2002) Genetic ablation of the t-SNARE SNAP-25 distinguishes mechanisms of neuroexocytosis. Nat Neurosci 5:19-26.

Wu LG, Borst JG (1999) The reduced release probability of releasable vesicles during recovery from short-term synaptic depression. Neuron 23:821-832.

Yamaguchi T, Dulubova I, Min SW, Chen X, Rizo J, Sudhof TC (2002) Sly1 binds to Golgi and ER syntaxins via a conserved N-terminal peptide motif. Dev Cell 2:295-305.

Yang B, Gonzalez Jr L, Prekeris R, Steegmaier M, Advani RJ, Scheller RH (1999) SNARE interactions are not selective. Implications for membrane fusion specificity. J Biol Chem 274:5649-5653. 